\title{
Occurrence and Risk Assessment of Dietary Exposure to Deoxynivalenol in Wheat-Based Products Based Different Wheat-Producing Area for the Inhabitants in Shanghai, China
}

\author{
Xianli Yang ${ }^{1,2, *, \dagger}$, Zhiyong Zhao ${ }^{1,+}$, Jianhua Wang ${ }^{1}{ }^{\mathbb{D}}$, Junhua Yang ${ }^{1}$, Hengchao $\mathrm{E}^{1}$, Bo Chen ${ }^{3} \mathbb{D}$, Pengzhen He ${ }^{4}$, \\ Yanglan Tan ${ }^{5}$ and Changyan Zhou ${ }^{1, *}$
}

check for

updates

Citation: Yang, X.; Zhao, Z.; Wang, J.; Yang, J.; E, H.; Chen, B.; He, P.; Tan, Y.; Zhou, C. Occurrence and Risk Assessment of Dietary Exposure to Deoxynivalenol in Wheat-Based Products Based Different Wheat-Producing Area for the Inhabitants in Shanghai, China. J. Fungi 2021, 7, 1015. https://doi.org/ 10.3390/jof7121015

Academic Editor: Kimiko Yabe

Received: 9 November 2021

Accepted: 25 November 2021

Published: 26 November 2021

Publisher's Note: MDPI stays neutral with regard to jurisdictional claims in published maps and institutional affiliations.

Copyright: (c) 2021 by the authors. Licensee MDPI, Basel, Switzerland. This article is an open access article distributed under the terms and conditions of the Creative Commons Attribution (CC BY) license (https:/ / creativecommons.org/licenses/by/ $4.0 /)$.
1 Laboratory of Quality \& Safety Risk Assessment for Agro-Products (Shanghai), Institute for Agro-Food Standards and Testing Technology, Ministry of Agriculture, Shanghai Academy of Agricultural Sciences, Shanghai 201403, China; zhaozhiyong@saas.sh.cn (Z.Z.); wangjianhua@saas.sh.cn (J.W.); yangjunhua@saas.sh.cn (J.Y.); ehengchao@saas.sh.cn (H.E.)

2 Shanghai Co-Elite Agro-Food Testing Technical Service Co., Ltd., Shanghai 201106, China

3 Department of Nutrition and Food Hygiene, School of Public Health, Fudan University, Shanghai 200433, China; chenb@fudan.edu.cn

4 College of Chemistry and Chemical Engineering, Mudanjiang Normal University, Mudanjiang 157012, China; hepengzhenadu@163.com

5 CAS Key Laboratory of Nutrition, Metabolism and Food Safety, Shanghai Institute of Nutrition and Health, Chinese Academy of Sciences, Shanghai 200031,China; yltan@sibs.ac.cn

* Correspondence: yangxianli@saas.sh.cn (X.Y.); zhouchangyan@saas.sh.cn (C.Z.)

+ Both X.Y. and Z.Z. rank as the first authors.

Abstract: Deoxynivalenol (DON) is one of the major mycotoxins that contaminate cereals. In this study, we determined the DON level in wheat-based products from Chinese five main production areas collected in Shanghai and calculated the daily intake of DON for inhabitants using the point evaluation and the probabilistic evaluation based on Monte Carlo simulation. The results showed the positive rates of $\mathrm{DON}$ in the products were higher than $80.0 \%$, with the concentrations ranging from 41.8 to $1110 \mu \mathrm{g} / \mathrm{kg}$. The estimated mean daily intakes of DON for 7- to 10-year-old children and adults groups were below $1 \mu \mathrm{g} / \mathrm{kg}$ bw/day, the provisional maximum tolerable daily intake (PMTDI) set by the Joint FAO/WHO Expert Committee on Food Additives (JECFA), suggesting no health risks for the consumers. However, the 99th percentiles of dietary DON exposures for children and adults exceeded the PMTDI, indicating adverse health effects might occur if the two groups intake highly contaminated wheat-based products. The potential health risks for the two groups exposed to DON in the wheat-based products from the Middle and Lower Yangtze Valley (MLYV) were higher than those from the other areas in China.

Keywords: risk assessment; deoxynivalenol; wheat-based products; wheat production area; inhabitants in Shanghai

\section{Introduction}

Deoxynivalenol (DON), one of the most important type B trichothecenes [1], is toxic and has adverse health effects on humans and animals [2]. The toxin is often detected worldwide in cereals and cereal-based products, including wheat and maize [3], especially in humid and rainy, temperate areas $[4,5]$.

DON occurrence in cereals has received increasing attention over the past few decades [6,7]. According to a study by Golge et al. [8], the positivity rate of DON, the most prevalent mycotoxin, in cereals and derived products collected in Turkey from 2015 to 2018 was 26\%. The contaminated incidence of DON in maize from Zimbabwe was $24 \%$, with the mean concentration of $217 \mu \mathrm{g} / \mathrm{kg}$ [9]. During 2008-2011, a total of 697 samples of wheat and wheat-based products in China were analyzed for multiple mycotoxins. The results showed 
that DON was the most frequently found toxin [10]. In particular, the DON concentration in nine wheat flour samples exceeded the Chinese regulatory limit of $1000 \mu \mathrm{g} / \mathrm{kg}$ recommended by the National Health and Family Planning Commission of China (NHFPC) [11]. According to a report, DON is the most abundant toxin detected in wheat samples in part of China [12]. In the study, the DON-positive rate was $90.8 \%(307 / 338)$ with average concentration $2846.7 \mu \mathrm{g} / \mathrm{kg}$ (range from $2 \mu \mathrm{g} / \mathrm{kg}$ to $59,278.0 \mu \mathrm{g} / \mathrm{kg}$ ), and the level of DON in $44.7 \%(151 / 338)$ samples exceeded the maximum tolerance limit of $1000 \mu \mathrm{g} / \mathrm{kg}$ regulated by Chinese government. Therefore, risk assessment of DON in food is necessary to guarantee consumer health.

Risk and hazard assessment of dietary exposure to DON in cereals and derivative products has been carried out $[9,13,14]$. Using the assessment methods for risk and hazard of environmental pollutants, assessment methods for substances in food have also been developed. Monte Carlo probabilistic simulation is often employed to predict the cumulative risk of DON in food. Sun et al. [15] assessed the dietary exposure to DON from cereals in China during the period 2010-2013 using Monte Carlo probabilistic simulations. Their results indicated that $75 \%$ of children and $90 \%$ of the general population and the adults were below the provisional maximum tolerable daily intake (PMTDI) of $1 \mu \mathrm{g} / \mathrm{kg}$ bw $/$ day set by the Joint FAO/WHO Expert Committee on Food Additives (JECFA) [16]. According to a risk assessment in Catalonia, Spain, DON could be detected in human urine from people who ingest bread, pasta, and pastries [17]. In Netherlands, the dietary intake of DON in wheat exceeded a provisional tolerable daily intake (PTDI) of $1.1 \mu \mathrm{g} / \mathrm{kg} \mathrm{bw} /$ day during September 1998 to January 2000. Moreover, 80\% of the 1-year-old children had a DON intake above the PTDI [18]. Nielsen et al. found fetuses can be exposed to DON during pregnancy, which may affect mothers and fetuses' health [19].

In China, the main wheat production areas, such as the Middle and Lower Yangtze Valley (MLYV), the Yellow and Huai Valley (YHV), the northeast area (NE), the northwest area (NW), and the southwest area (SW), are located in the wet northern temperate zone, shown in Figure 1 [20]. Therefore, DON is frequently found in China [21-23], especially in rainy years. In Shanghai, the inhabitants consume about 6.34 million tons of grains every year, $80 \%$ of which is supplied from other geographical areas [24]. Quality levels of cereal products and the impact on consumer health are different for cereal from different areas. The risk assessment for the dietary intake of DON in cereal-based products from different geographical has not been reported. Nevertheless, a previous study has evaluated the dietary exposure to DON in cereals and cereal-based products for adults and children in Shanghai [14].

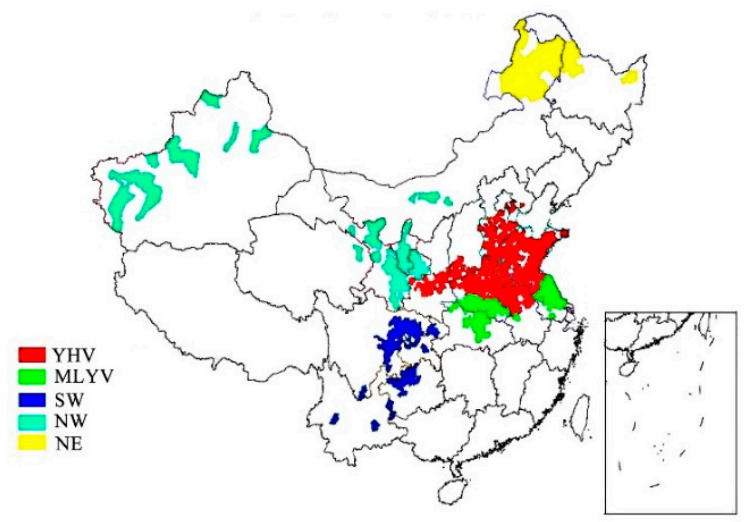

Figure 1. Sketch map of the five main wheat production areas in China (YHV, the Yellow and Huai Valley; MLYV, the Middle and Lower Yangtze Valley; SW, the southwest area; NW, the northwest area; NE, the northeast area) [20].

The objective of this study is to: (1) analyze the occurrence of DON in wheat-based products from Chinese five main production areas collected in Shanghai and (2) evaluate the 
potential health risk of exposure to DON by point evaluation and probabilistic evaluation for inhabitants in Shanghai.

\section{Materials and Methods}

\subsection{Toxins and Chemicals}

DON standard solution, ammonium acetate, and formic acid were purchased from Sigma-Aldrich (St. Louis, MO, USA) and stored at $-20^{\circ} \mathrm{C}$ until use. The standard solution was diluted in acetonitrile prior to analysis to obtain the working solution. HPLC-grade acetonitrile and methanol were obtained from Merck (Darmstadt, Germany). Ultrapure water was produced by a Milli-Q filtration system (Bedford, MA, USA). All of the other reagents were of HPLC or analytical grade.

\subsection{Samples}

A total of 340 samples of wheat-based products were randomly collected in Shanghai markets, including supermarkets, chain stores, and farm product markets, in all 16 city districts. Information concerning the geographic origin of the samples was recorded. All of the samples were ground into fine powder and stored at $-20^{\circ} \mathrm{C}$ under dry and dark conditions before analysis.

\subsection{Determination of DON Concentration in Wheat-Based Products}

The wheat-based products were pretreated according to the standard operating procedures set by the NHFPC [25]. Of each sample, $25 \mathrm{~g}$ was mixed in $100 \mathrm{~mL}$ water. The mixture was shaken for $20 \mathrm{~min}$ and centrifuged at $6000 \mathrm{rpm}$ for $10 \mathrm{~min}$. The supernatant was collected and centrifuged at 10,000 rpm for $5 \mathrm{~min}$. The supernatant was passed through DonStar immunoaffinity column (3 mL of antibody gel, Romer Labs, Inc. Union, MO, USA) at a rate of $2 \mathrm{~mL} / \mathrm{min}$, and then $5 \mathrm{~mL}$ of PBS and $5 \mathrm{~mL}$ of water were passed through the column at a flow rate of 1-2 drops per second. The columns were eluted with $2 \mathrm{~mL}$ methanol at a rate of 1 drop per second and then dried by nitrogen gas flow at $50^{\circ} \mathrm{C}$. The residues were reconstituted in $1 \mathrm{~mL}$ methanol/water $(20 / 80, v / v)$ solution and passed through a $0.22-\mu \mathrm{m}$ nylon filter (Millipore Corp., Billerica, MA, USA). The filtrate was collected for UPLC-MS/MS analysis.

Sample analysis was performed using an Acquity ultra high-performance liquid chromatography (UHPLC) system (Waters, Eschborn, Germany) coupled to a triple quadrupole mass spectrometer 5500 (AB Sciex, Darmstadt, Germany) equipped with an electrospray ionization source operating in the positive mode. Chromatographic separation was carried out on an Acquity BEH C18 column $(2.1 \mathrm{~mm} \times 100 \mathrm{~mm}, 1.8 \mu \mathrm{m}$; Waters) at the temperature of $40^{\circ} \mathrm{C}$. The mobile phase consisted of water containing $5 \mathrm{mmol} / \mathrm{L}$ ammonium acetate (solvent A) and methanol (solvent B). A linear gradient program was applied at a flow rate of $300 \mu \mathrm{L} / \mathrm{min}$ as follows: 0-1 $\mathrm{min}, 90 \% \mathrm{~A} ; 1-5 \mathrm{~min}, 10 \% \mathrm{~A} ; 5-6 \mathrm{~min}, 10 \% \mathrm{~A} ; 6-6.5 \mathrm{~min}$, $90 \% \mathrm{~A}$; and $6.5-8 \mathrm{~min}, 90 \% \mathrm{~A}$. The sample temperature was set at $4{ }^{\circ} \mathrm{C}$, and the sample injection volume was $5 \mu \mathrm{L}$. The operating parameters of $\mathrm{AB}$ Sciex 5500 were set as ion spray voltage, $5500 \mathrm{~V}$; interface heater temperature, $450^{\circ} \mathrm{C}$; curtain gas, $40 \mathrm{psi}$; ion source gas 1 , $50 \mathrm{psi}$; ion source gas 2, $50 \mathrm{psi}$; and collision activated dissociation (CAD) gas, medium. Multiple reactions monitoring (MRM) mode was employed for quantitative analysis. DON was monitored using the followed fragmentation pathways: $\mathrm{m} / \mathrm{z} 297.3 \rightarrow \mathrm{m} / \mathrm{z} 203$ (quantifier signal), $\mathrm{m} / \mathrm{z} 297.3 \rightarrow \mathrm{m} / \mathrm{z} 175.1$ (confirmation signal). Data acquisition and processing were performed using Analyst 1.6.2 software (AB Sciex). The recovery of the method was $82.3-95.2 \%$ in the spiked wheat samples. The DON limit of detection (LOD) of the standard method is $5 \mu \mathrm{g} / \mathrm{kg}$, and the limit of quantitation (LOQ) of the standard method is $15 \mu \mathrm{g} / \mathrm{kg}$.

\subsection{Dietary Consumption Data}

The data on food consumption of children were obtained from a Shanghai Food Consumption Survey (SHFCS) performed by Fudan University between 2012 and 2014. The detail of the SHFCS was described in previous studies [14,26]. In this study, the survey 
collected the food consumption data of 125 ( 65 boys and 60 girls) 7- to 10-year-old children and 1269 (aged 17-60 years, 608 adult men and 661 adult women) participants residing in Shanghai. A face-to-face questionnaire survey was conducted to record the following information: food types, amount and frequency of eating, 24-h dietary recall, and real-time measurement of body weight.

\subsection{Risk Assessment}

Two mathematical approaches, i.e., point evaluation and probability evaluation, were employed to assess the health risk resulting from DON intake through wheat-based products. The point evaluation was performed by multiplying the amount of food consumption (mean or percentile) with the DON concentration in each sample. The corresponding equations are the following [27]:

$$
\begin{gathered}
y=(x \cdot c) / w \\
\operatorname{MOS}=y / \mathrm{TDI}
\end{gathered}
$$

where, $y$ is the daily exposure level of an individual to a specific substance ( $\mu \mathrm{g} / \mathrm{kg} \mathrm{bw} /$ day), $x$ is the mean amount of food consumption $(\mathrm{g} / \mathrm{d}), c$ is the content of a substance in food, and $w$ is the mean body weight $(\mathrm{kg})$. The MOS (Equation (2)) is calculated by dividing the daily exposure level by the TDI, which is defined as the maximum amount of one substance that can be ingested daily over a lifetime with no appreciable health risk. MOS values lower than 1 are generally considered to indicate no risk to human health. If the MOS value is greater than 1 , the exposure risk of one specific substance is undesirable.

The uncertainty caused by the small size of each sample study and unreliability of food consumption data can result in inaccurate risk analysis. The Monte Carlo model is used to quantify and decrease the uncertainty in the health risk assessment. In our study, the cumulative exposure of each substance was performed using the Monte Carlo model operated in @RISK Version 5.0 (Palisade, Ithaca, NY, USA) in combination with Microsoft Excel 2016. The daily food consumption amounts and the sample residue concentration data were input into @RISK software and integrated by Monte Carlo sampling with a number of 5000 iterations.

\section{Results and Discussion}

\subsection{The Origin of Wheat-Based Products Sold in Shanghai}

In the present study, 340 wheat-based products were randomly collected from Shanghai markets, including supermarkets, chain stores, and farm product markets, in all 16 city districts. The number of samples from every district is shown in Figure 2a. The wheat samples in Shanghai mainly originates from MLYV (35.9\%), YHV (41.2\%), NE (7.35\%), NW $(7.35 \%)$, and SW $(2.9 \%)$, as shown in Figure $2 \mathrm{~b}$. The wheat samples from MLYV and YHV together represent $77.1 \%$ of the total. This is not surprising, as these are currently the main wheat-producing areas in China [28]. 


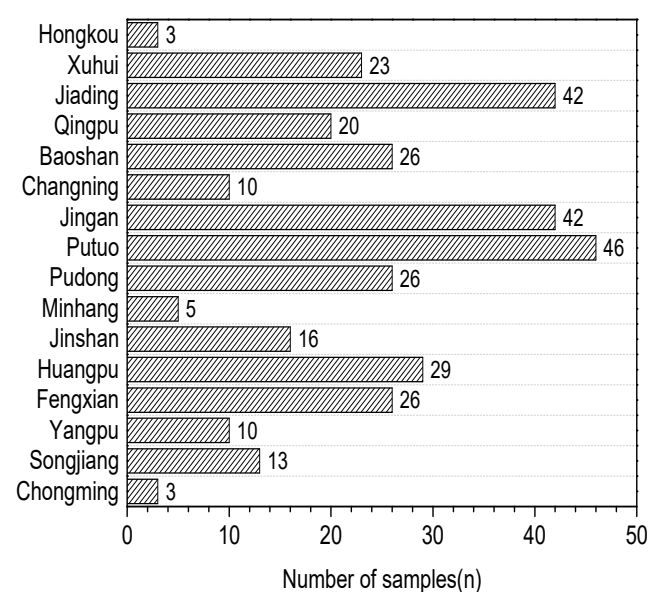

(a)

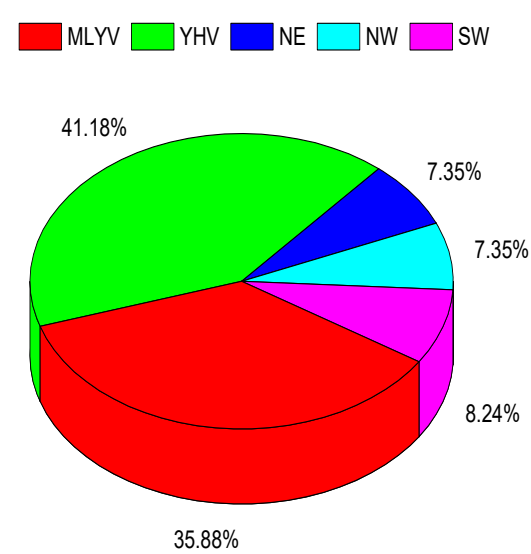

(b)

Figure 2. (a) The number of wheat-based products samples and the sample collection location in Shanghai city; (b) the proportion of the geographic origin of the samples.

\subsection{Dietary Intake of Children and Adults in Shanghai}

In Shanghai, the daily diets of 125 seven- to 10 -year-old children ( 65 boys and 60 girls) and 1269 adults (608 adult men and 661 adult women) were surveyed, as shown in Table 1. The mean and median daily intake of wheat flour products, $98.7,67.0 \mathrm{~g} / \mathrm{d}$ for boys and $75.1,57.9 \mathrm{~g} / \mathrm{d}$ for girls, were lower than the mean consumption of wheat products for teenagers $(129.6 \mathrm{~g} / \mathrm{d})$ in Parana, Brazil [29]. However, the 90th percentile (230.0, $181.1 \mathrm{~g} / \mathrm{d}$ ), 95th percentile (303.4, $257.9 \mathrm{~g} / \mathrm{d})$, 97.5th percentile $(361.5,285.5 \mathrm{~g} / \mathrm{d})$, and 99th percentile $(513.6,309.4 \mathrm{~g} / \mathrm{d})$ of daily intake for seven- to 10-year-old children were higher than the value. Similarly, the mean and median daily intake of wheat flour products of $95.5,67.0 \mathrm{~g} / \mathrm{d}$ for adult men and 72.2, $40.0 \mathrm{~g} / \mathrm{d}$ for adult women were lower than the mean consumption of wheat products for adults $(117.6 \mathrm{~g} / \mathrm{d})$. The 90th percentile $(250.0,181.1 \mathrm{~g} / \mathrm{d})$, , 95th percentile $(303.4,257.9 \mathrm{~g} / \mathrm{d})$, 97.5th percentile $(361.5,285.5 \mathrm{~g} / \mathrm{d})$, and 99th percentile $(513.6,309.4 \mathrm{~g} / \mathrm{d})$ of daily intake for seven- to 10-year-old children exceeded the mean consumption of wheat products for adults in Parana, Brazil. The 97.5th and 99th percentiles of daily intake of wheat flour products for children and adults were also higher than the average consumption for adults $(267.7 \mathrm{~g} / \mathrm{d})$ in Serbia [30].

Table 1. The daily intake of wheat-based products for inhabitants in Shanghai (g/d).

\begin{tabular}{|c|c|c|c|c|c|c|}
\hline Group & Mean \pm SD & Median & $\begin{array}{c}\text { 90th } \\
\text { Percentile }\end{array}$ & $\begin{array}{c}\text { 95th } \\
\text { Percentile }\end{array}$ & $\begin{array}{c}\text { 97.5th } \\
\text { Percentile }\end{array}$ & $\begin{array}{c}\text { 99th } \\
\text { Percentile }\end{array}$ \\
\hline Boys ${ }^{1}$ & $98.7 \pm 120.5$ & 67.0 & 230.0 & 303.4 & 361.5 & 513.6 \\
\hline Girls ${ }^{2}$ & $75.1 \pm 83.8$ & 57.9 & 181.1 & 257.9 & 285.5 & 309.4 \\
\hline Adult men ${ }^{3}$ & $95.5 \pm 111.8$ & 67.0 & 250.0 & 313.3 & 401.7 & 488.4 \\
\hline Adult women ${ }^{4}$ & $72.2 \pm 98.2$ & 40.0 & 200.0 & 257.0 & 328.5 & 427.2 \\
\hline
\end{tabular}

${ }^{1}$ The mean weight of 7- to 10 -year-old boys is $38.3 \mathrm{~kg} ;{ }^{2}$ The mean weight of 7 - to 10 -year-old girls is $33.4 \mathrm{~kg} ;{ }^{3}$ The mean weight of adult men is $62.7 \mathrm{~kg} ;{ }^{4}$ The mean weight of adult women is $54.0 \mathrm{~kg}$.

\subsection{Contamination Levels of Wheat Flour Products}

Of the 340 collected samples of wheat flour products, 288 samples $(84.7 \%)$ were DON positive, as shown in Table 2. The mean, median, and 90th, 95th, 97.5th, and 99th percentiles of DON content in products with wheat from different areas are also shown in Table 2. The positivity rate of DON in each area was higher than $80.0 \%$. The positivity rate of DON in NE was $100 \%(25 / 25)$. The mean DON content in MLYV, YHV, and total samples was $288.2 \pm 269.6 \mu \mathrm{g} / \mathrm{kg}$ (ranging from 41.8 to $1110 \mu \mathrm{g} / \mathrm{kg}$ ), $148.7 \pm 188.8 \mu \mathrm{g} / \mathrm{kg}$ (ranging from 42.0 to $896 \mu \mathrm{g} / \mathrm{kg}$ ), and $205.6 \pm 234.7 \mu \mathrm{g} / \mathrm{kg}$, respectively. The values of the other areas were lower. Moreover, the 99th percentiles of DON content in MLYV, 
YHV, and total samples were $972.9 \mu \mathrm{g} / \mathrm{kg}, 886.3 \mu \mathrm{g} / \mathrm{kg}$, and $934.2 \mu \mathrm{g} / \mathrm{kg}$, respectively, i.e., all three slightly below the maximum limit of $1000 \mu \mathrm{g} / \mathrm{kg}$ in raw wheat and derived foods [11] as determined by the Codex Alimentarius Commission (CAC) [31]. However, the 95th percentile of DON content in MLYV and total samples and the 97.5th percentile in YHV exceeded the maximum limits of 750 and $500 \mu \mathrm{g} / \mathrm{kg}$ established by the European Commission (EC) [32]. Areas with higher humidity showed higher DON levels in the wheat samples [33].

Table 2. DON contamination level in wheat-based products in Shanghai ( $\mu \mathrm{g} / \mathrm{kg})$.

\begin{tabular}{|c|c|c|c|c|c|c|c|c|c|}
\hline $\begin{array}{c}\text { Geographic } \\
\text { Origin of } \\
\text { the } \\
\text { Wheat }\end{array}$ & $\begin{array}{c}\text { Number } \\
\text { of } \\
\text { Samples } \\
(n)\end{array}$ & $\begin{array}{l}\text { Number } \\
\text { of } \\
\text { Positivity } \\
(\%)\end{array}$ & $\begin{array}{l}\text { Range of } \\
\text { DON in } \\
\text { Positivity } \\
\text { Samples }\end{array}$ & Mean \pm SD $^{1}$ & Median & $\begin{array}{c}\text { 90th } \\
\text { Percentile }\end{array}$ & $\begin{array}{c}\text { 95th } \\
\text { Percentile }\end{array}$ & $\begin{array}{c}\text { 97.5th } \\
\text { Percentile }\end{array}$ & $\begin{array}{c}\text { 99th } \\
\text { Percentile }\end{array}$ \\
\hline MLYV & 122 & $103(84.4)$ & $41.8-1110$ & $288.2 \pm 269.6$ & 202.5 & 756 & 850.9 & 924.6 & 972.9 \\
\hline YHV & 140 & $117(83.6)$ & $42.0-896$ & $148.7 \pm 188.8$ & 92.3 & 350.4 & 533.4 & 860.5 & 886.3 \\
\hline NE & 25 & $25(100)$ & $43.3-297$ & $137.4 \pm 88.1$ & 132.6 & 235.4 & 266.2 & 281.7 & 290.9 \\
\hline NW & 25 & $20(80.0)$ & 46.6-131 & $66.7 \pm 46.4$ & 67.4 & 112 & 121.4 & 126.1 & 128.9 \\
\hline SW & 28 & $23(82.1)$ & $48.2-120$ & $70.4 \pm 42.3$ & 89.3 & 107.6 & 113.7 & 116.7 & 118.6 \\
\hline Total & 340 & $288(84.7)$ & $41.8-1110$ & $205.6 \pm 234.7$ & 129.4 & 500.6 & 840.2 & 879.1 & 934.2 \\
\hline
\end{tabular}

${ }^{1}$ The value of limit of detection (LOD) was assigned to all results below the LOD.

The results, a DON positivity rate of $86.7 \%$ and a mean concentration of $325 \pm 293 \mu \mathrm{g} / \mathrm{kg}$ (range from 17.5 to $976 \mu \mathrm{g} / \mathrm{kg}$ ), were comparable with results from Serbia [34], higher than the reported DON positivity rate of $43.2 \%$ and mean concentration of $18.8 \mu \mathrm{g} / \mathrm{kg}$ (range from 3.1 to $172.9 \mu \mathrm{g} / \mathrm{kg}$ ) in 188 cereal samples (consisting of rice, brown rice, barley, and maize) in South Korea [35], and lower than the DON positivity rate of $97.2 \%$ and mean concentration of $591 \mu \mathrm{g} / \mathrm{kg}$ (range from 60 to $1720 \mu \mathrm{g} / \mathrm{kg}$ ) in biscuits from Brazil [36]. In addition, the results were lower than the values reported in 2013 (positivity rate of $98.7 \%$, mean concentration of $879.3 \pm 1127.8 \mu \mathrm{g} / \mathrm{kg}$ ), 2014 (positivity rate of $84.7 \%$, mean concentration of $627.8 \pm 640.5 \mu \mathrm{g} / \mathrm{kg}$ ), and 2015 (positivity rate of $98.7 \%$, mean concentration of $1628.6 \pm 2168.0 \mu \mathrm{g} / \mathrm{kg}$ ) from wheat grown in Jiangsu, China [37].

As well known, temperature and rainfall are the key climatic factors having a great impact on the occurrence of wheat Fusarium head blight (FHB) as well as the contamination level of mycotoxins [38,39]. The climate conditions in the two wheat-producing areas (MLYV and YHV) are humid and warm during wheat cultivation, especially at the flowering and grain filling stages $[4,40]$, which are contributed to Fusarium infection and DON synthesis [41]. This is why the average concentration of DON in wheat produced in MLYV is higher than that in NE, NW, and SW. The results are comparable to previously published studies, in which DON levels of wheat samples collected from Northwestern of China are lower than those in samples collected in the Yangtze-Huaihe river basin region $[4,42]$.

\subsection{Point Evaluation of DON Dietary Exposure}

Based on the DON content in wheat flour and the dietary intake, dietary DON exposure through wheat-based products from different areas was calculated for seven- to 10-year-old children and adults from Shanghai. The results are shown in Tables 3-6.

The mean dietary DON exposure of $0.530 \mu \mathrm{g} / \mathrm{kg}$ bw/day (i.e., 53.0\% of the PMTDI value of $1 \mu \mathrm{g} / \mathrm{kg} \mathrm{bw} /$ day [43]) for 7- to 10-year-old boys in total samples was higher than in all of the areas except MLYV $(0.743 \mu \mathrm{g} / \mathrm{kg}$ bw/day). The median dietary exposure in each area for the four groups was below the PMTDI value. In addition, the 90th percentiles of dietary exposures from NE for adults, the 90th and 95th percentiles of dietary exposures from NW for children, and the 90th, 95th and 97.5th percentiles of dietary exposures for adults from NW were below $1 \mu \mathrm{g} / \mathrm{kg}$ bw/day. These results indicate that there are no 
increased health risks for most seven- to 10-year-old children and adults caused by recent DON exposure through the wheat-based products from the above areas.

Table 3. $\mathrm{T}$ The estimated dietary DON exposure through wheat-based products from different areas for 7- to 10-year-old boys determined by point evaluation $(\mu \mathrm{g} / \mathrm{kg}$ bw $/$ day).

\begin{tabular}{ccccccc}
\hline Geographic Origin of the Wheat & Mean & Median & $\begin{array}{c}\text { 90th } \\
\text { Percentile }\end{array}$ & $\begin{array}{c}\text { 95th } \\
\text { Percentile }\end{array}$ & $\begin{array}{c}\text { 97.5th } \\
\text { Percentile }\end{array}$ & $\begin{array}{c}\text { 99th } \\
\text { Percentile }\end{array}$ \\
\hline MLYV & 0.743 & 0.355 & 4.55 & 6.75 & 8.74 \\
YHV & 0.383 & 0.162 & 2.11 & 4.23 & 8.13 & 13.1 \\
NE & 0.354 & 0.232 & 1.42 & 2.11 & 2.66 & 3.90 \\
NW & 0.172 & 0.118 & 0.673 & 0.963 & 1.19 \\
SW & 0.182 & 0.156 & 0.647 & 0.902 & 1.10 \\
Total & 0.530 & 0.227 & 3.01 & 6.66 & 8.31 \\
\hline
\end{tabular}

Table 4. The estimated dietary DON exposure through wheat-based products from different areas for 7- to 10-year-old girls determined by point evaluation $(\mu \mathrm{g} / \mathrm{kg}$ bw/day).

\begin{tabular}{ccccccc}
\hline Geographic Origin of the Wheat & Mean & Median & $\begin{array}{c}\text { 90th } \\
\text { Percentile }\end{array}$ & $\begin{array}{c}\text { 95th } \\
\text { Percentile }\end{array}$ & $\begin{array}{c}\text { 97.5th } \\
\text { Percentile }\end{array}$ & $\begin{array}{c}\text { 99th } \\
\text { Percentile }\end{array}$ \\
\hline MLYV & 0.648 & 0.351 & 4.10 & 6.57 & 7.90 & 9.01 \\
YHV & 0.334 & 0.160 & 1.90 & 4.12 & 7.35 & 8.21 \\
NE & 0.309 & 0.230 & 1.28 & 2.06 & 2.41 & 2.69 \\
NW & 0.150 & 0.117 & 0.607 & 0.937 & 1.08 & 1.19 \\
SW & 0.158 & 0.155 & 0.583 & 0.878 & 0.997 & 1.10 \\
Total & 0.462 & 0.224 & 2.71 & 6.49 & 7.51 & 8.65 \\
\hline
\end{tabular}

Table 5. The estimated dietary DON exposure through wheat-based products from different areas for adult men determined by point evaluation $(\mu \mathrm{g} / \mathrm{kg}$ bw/day).

\begin{tabular}{ccccccc}
\hline Geographic Origin of the Wheat & Mean & Median & $\begin{array}{c}\text { 90th } \\
\text { Percentile }\end{array}$ & $\begin{array}{c}\text { 95th } \\
\text { Percentile }\end{array}$ & $\begin{array}{c}\text { 97.5th } \\
\text { Percentile }\end{array}$ & $\begin{array}{c}\text { 99th } \\
\text { Percentile }\end{array}$ \\
\hline MLYV & 0.439 & 0.216 & 3.01 & 4.25 & 5.95 & 7.58 \\
YHV & 0.226 & 0.099 & 1.40 & 2.67 & 5.51 & 6.90 \\
NE & 0.209 & 0.142 & 0.939 & 1.33 & 1.81 & 2.27 \\
NW & 0.102 & 0.072 & 0.447 & 0.607 & 0.808 & 1.01 \\
SW & 0.107 & 0.095 & 0.429 & 0.568 & 0.748 & 0.924 \\
Total & 0.313 & 0.138 & 1.99 & 4.20 & 5.63 & 7.28 \\
\hline
\end{tabular}

Table 6. The estimated dietary DON exposure through wheat-based products from different areas for adult women determined by point evaluation $(\mu \mathrm{g} / \mathrm{kg}$ bw/day).

\begin{tabular}{ccccccc}
\hline Geographic Origin of the Wheat & Mean & Median & $\begin{array}{c}\text { 90th } \\
\text { Percentile }\end{array}$ & $\begin{array}{c}\text { 95th } \\
\text { Percentile }\end{array}$ & $\begin{array}{c}\text { 97.5th } \\
\text { Percentile }\end{array}$ & $\begin{array}{c}\text { 99th } \\
\text { Percentile }\end{array}$ \\
\hline MLYV & 0.385 & 0.150 & 2.80 & 4.05 & 5.63 & 7.70 \\
YHV & 0.199 & 0.068 & 1.30 & 2.54 & 5.24 & 7.01 \\
NE & 0.184 & 0.098 & 0.872 & 1.27 & 1.71 & 2.30 \\
NW & 0.089 & 0.050 & 0.415 & 0.578 & 0.767 & 1.020 \\
SW & 0.094 & 0.066 & 0.399 & 0.541 & 0.710 & 0.938 \\
Total & 0.275 & 0.096 & 1.85 & 3.99 & 5.348 & 7.39 \\
\hline
\end{tabular}

However, the 90th percentiles of dietary exposure for boys from MLYV (4.55 $\mu \mathrm{g} / \mathrm{kg}$ bw/day), YHV (2.11 $\mu \mathrm{g} / \mathrm{kg}$ bw/day), NE (1.42 $\mu \mathrm{g} / \mathrm{kg}$ bw/day), and total samples $(3.01 \mu \mathrm{g} / \mathrm{kg}$ bw / day) were all above the PMTDI. The 97.5th percentiles from NW and SW for seven- to 10-year-old girls were 1.19 and $1.10 \mu \mathrm{g} / \mathrm{kg}$ bw/day, respectively, also 
exceeding the PMTDI. For girls, the 90th percentiles of dietary exposure from MLYV, YHV, $\mathrm{NE}$, and total samples were 4.10, 1.90, 1.28, and $2.71 \mu \mathrm{g} / \mathrm{kg}$ bw/day, respectively, which were all above the PMTDI as well. Additionally, the 97.5th percentile of DON exposure from NW $(1.08 \mu \mathrm{g} / \mathrm{kg}$ bw/day) and the 99th percentile from SW $(1.10 \mu \mathrm{g} / \mathrm{kg}$ bw/day $)$ were higher than the PMTDI. Similarly, the 90th, 95th, 97.5th and 99th percentiles of dietary exposures for adults from MLYV, YHV, total samples, the 95th, 97.5th, and 99th percentiles of dietary exposures for adults from NE and 99th percentiles of dietary exposures for adults from NW were above the PMTDI. The results indicate that extreme DON exposure values do pose risks. The risk of DON intake through products from MLYV is higher than that from the four other areas. Seven- to 10-year-old children showed higher levels of dietary DON intake than adults.

Our results are consistent with previous reports. The estimated daily DON intake from cereal-based baby food for four-, five-, six-, and seven- to 12-month-old infants $(n=60)$ in Cantabria and Aragón, Spain [44], were $0.25,0.28,0.32$, and $0.36 \mu \mathrm{g} / \mathrm{kg} \mathrm{bw} / \mathrm{day}$, respectively, lower than the tolerable daily intake (TDI) of $1 \mu \mathrm{g} / \mathrm{kg}$ bw / day established by the European Food Safety Authority (EFSA) [45].The results were higher than the dietary DON exposure of children and of adults through cereal-based foods $(n=159)$ of $0.05 \mu \mathrm{g} / \mathrm{kg}$ bw/day and $0.006 \mu \mathrm{g} / \mathrm{kg}$ bw/day in Valencia, Spain [46].Those results indicated the consumers had no increased health risks. However, the daily DON intakes of adolescents in Belgium [47], two- to six-year-old children in Australia [47], and children in Serbia [35] of 1.26, 3.16, and $1.7 \mu \mathrm{g} / \mathrm{kg}$ bw/day, respectively, were higher than the PMTDI. Moreover, the daily DON intakes of adults in Brazil [47] $(1.45 \mu \mathrm{g} / \mathrm{kg}$ bw/day) and Belgium [47] (1.08 $\mu \mathrm{g} / \mathrm{kg}$ bw/day) were higher than the PMTDI of $1 \mu \mathrm{g} / \mathrm{kg}$ bw/day, suggesting an increased health risk is associated with wheat product consumption.

Compared with other studies in China, the mean DON exposure through wheat-based products in our study is lower than that from wheat flour products for Chinese children $(3.9 \mu \mathrm{g} / \mathrm{kg} \mathrm{bw} /$ day $)$ and adults $(1.3 \mu \mathrm{g} / \mathrm{kg}$ bw/day) [48]. Wang et al. [49] reported the 90th percentile of exposure to DON through wheat flour- and corn-based products collected from Chinese supermarkets and farmers markets for three- to 13-year-old children $(2.066 \mu \mathrm{g} / \mathrm{kg}$ bw/day) and for $\geq 14-$ year-old $(1.28 \mu \mathrm{g} / \mathrm{kg} \mathrm{bw} /$ day $)$, higher than PMTDI, indicating the consumer were at high risk. Sun et al. [15] found the 90th percentile of estimated dietary DON intake through cereals and cereal-based foods for two- to sixyear-old children was $1.2 \mu \mathrm{g} / \mathrm{kg}$ bw $/$ day, $120 \%$ of the PMTDI, and the 99th percentile of estimated dietary DON intake through cereals and cereal-based foods for adults was $3.0 \mu \mathrm{g} / \mathrm{kg} \mathrm{bw} /$ day, three times the PMTDI, indicating the consumption of wheat flourand wheat-based products poses a potential health risk in China. Deng et al. [50] estimated the mean daily DON intake for two- to 12 -year-old children $(2.09 \mu \mathrm{g} / \mathrm{kg} \mathrm{bw} / \mathrm{day})$, for 13- to 18-year-old adolescents (3.08 $\mu \mathrm{g} / \mathrm{kg}$ bw / day), and for 18- to 65-year-old adults $(1.41 \mu \mathrm{g} / \mathrm{kg}$ bw/day) in Henan, China, and reported values exceeding the PMTDI. Similarly, the mean and the 90th percentile of estimated dietary DON intake for seven- to 12-year-old children in Henan, China, were 3.80 and $9.93 \mu \mathrm{g} / \mathrm{kg}$ bw / day, respectively, 3.80 and 9.93 times the PMTDI [51]. Wang et al. [52] found a mean DON exposure through wheat-based products for seven- to 12-year-old children, for 13- to 17-year-old adolescents, and for 18- to 59-year-old adults of 3.2, 2.5, and $2.4 \mu \mathrm{g} / \mathrm{kg}$ bw/day in Anhui, China, which is 3.2, 2.5, and 2.4 times the PMTDI, respectively. In contrast, Liu et al. [21] found mean levels of daily DON intake through wheat products in Hebei province, China, for adults of $0.49 \mu \mathrm{g} / \mathrm{kg} \mathrm{bw} /$ day in 2011, $0.86 \mu \mathrm{g} / \mathrm{kg}$ bw/day in 2012, and $0.56 \mu \mathrm{g} / \mathrm{kg}$ bw/day in 2013, which were all below the PMTDI. Also, the mean and median dietary DON intake (as calculated from urinary values) for seven- to 12-year-old children and 18- to 59-year-old adults in Sichuan, China, were reported to be 0.60 and $0.41 \mu \mathrm{g} / \mathrm{kg}$ bw $/$ day, respectively, less than or equal to the PMTDI, indicating there is no health risk for this age group [51].

In addition, it is worth noting the areas where higher DON intake was the previously reported, such as Henan and Anhui, lie in MLYV and YHV, and the lower-intake areas, such as Hebei and Sichuan, lie in the other areas. In MLYV and YHV, abundant rainfall 
and warm temperatures [53], provides a superior environment for F. asiaticum, one of its metabolites is DON. Our results on DON intake through consumption of wheat from different areas are comparable to previous results.

\subsection{Probabilistic Evaluation of Dietary DON Exposure}

Point evaluation, which does not consider the variability and uncertainty of food consumption and contamination levels, might give an overevaluation of the exposure levels [27]. Therefore, a full probabilistic method, the Monte Carlo model, was used for further investigation to provide more realistic estimated DON exposures through wheat from different wheat producing areas for seven- to 10-year-old children and adults, as shown in Figure 3.
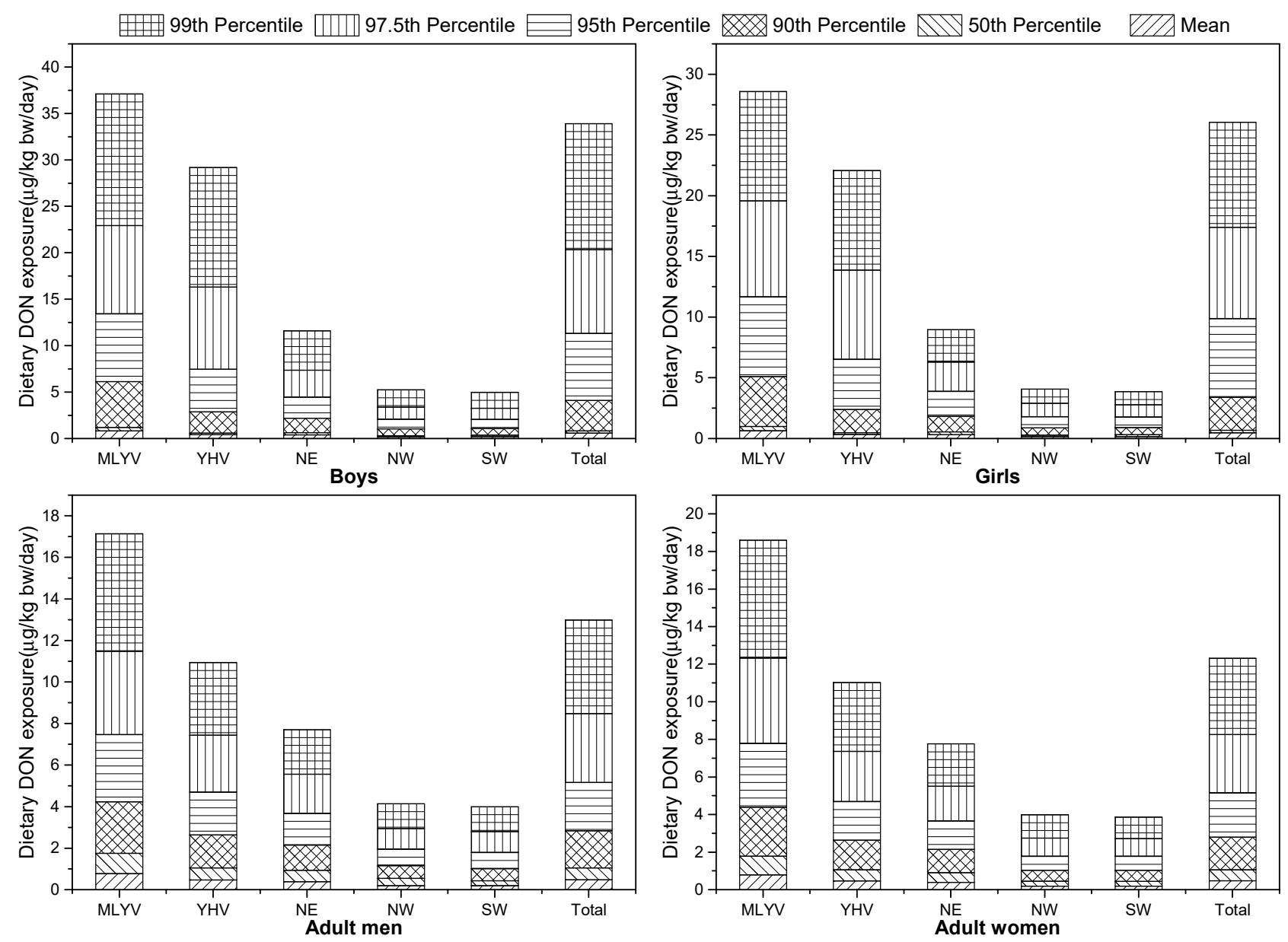

Figure 3. The estimated dietary DON exposure through wheat-based products from different production areas for 7- to 10-year-old children and adults determined by probabilistic evaluation.

The mean and median probabilistic daily DON intake from each area were below the PMTDI, meaning that the margin of safety (MOS) values were less than 1 and that there was no increased health risk for seven- to 10-year-old children and adults due to DON intake through wheat products. The mean probabilistic DON exposure values were similar to the point evaluation values, which were comparable to previous reports from different countries. Assunção et al. [54] found that the mean probabilistic dietary DON exposure through cereal-based products for Portuguese children $(n=52)$ was $0.0539 \mu \mathrm{g} / \mathrm{kg} \mathrm{bw} / \mathrm{day}, 5.39 \%$ of the PMTDI. Additionally, the probabilistic estimated daily DON intake through wheatbased products for adults in Croatia $(0.121 \mu \mathrm{g} / \mathrm{kg}$ bw /day), Greece $(0.181 \mu \mathrm{g} / \mathrm{kg} \mathrm{bw} /$ day $)$, and Serbia $(0.262 \mu \mathrm{g} / \mathrm{kg}$ bw/day) was below the PMTDI [55]. Ortiz et al. [56] used firstorder Monte Carlo simulation based on 10,000 iterations and estimated a daily DON 
exposure through wheat noodles for children aged 0-23 months $(n=128)$ in Ecuadorian highlands of $0.0915 \mu \mathrm{g} / \mathrm{kg}$ bw/day.

However, the 90th percentile of daily DON intake through wheat-based products from MLYV, YHV, NE, and total samples, the 95th percentile from NW, and the 97.5th percentile from SW for seven- to 10-year-old boys were higher than the PMTDI. Moreover, the 90th percentile of daily DON intake through wheat-based products from MLYV, YHV, NE, and total samples, the 97.5th percentile from NW, and the 99th percentile from SW for sevento 10-year-old girls were higher than the PMTDI. Similarly, the 90th percentile of daily DON intake through wheat-based products from MLYV, YHV, NE, and total samples, the 97.5th percentile from $\mathrm{SW}$, and the 99th percentile from NW for adult men were higher than the PMTDI. The 90th percentile of daily DON intake through wheat-based products from MLYV, YHV, NE, total samples, and the 99th percentile from NW and SW for adult women were higher than the PMTDI. These results indicate that the MOS values were more than 1 and increased health risks might exist for the group if they ingest highly contaminated wheat. Other publications reported similar results. The 75th percentile of DON intakes through wheat flour for Chinese children and adults, as estimated from various online sources, are 6.5 and $2.2 \mu \mathrm{g} / \mathrm{kg}$ bw/day [49], respectively. The highest estimated daily DON exposure values in Europe $(1.04 \mu \mathrm{g} / \mathrm{kg}$ bw/day), as calculated from urine samples, were reported for workers in the production area of a Portuguese dough company $(n=21)$ [57].

In conclusion, the risk of DON intake through wheat-based products from MLYV is higher than that from the four other areas, and children showed higher levels of dietary DON exposure than adults. These results are similar to our point evaluation analysis.

\section{Conclusions}

We performed a quantitative cumulative health risk assessment of DON intake through wheat-based products from Chinese five main production areas for seven- to 10-year-old children and adults in Shanghai by the point evaluation and the probabilistic evaluation based on Monte Carlo simulation. The results showed the mean dietary DON intake was lower than the PMTDI. Children showed higher dietary DON exposure values than adults. However, the wheat-based products from MLYV posed higher health risk compared to that from the other areas. In addition, the 99th percentiles of dietary DON exposures exceeded the PMTDI, suggesting adverse health effects might occur if the consumers ingest highly contaminated wheat-based products. Furthermore, we would like to make the following recommendations: (1) Wheat from high-contamination production areas should be routinely monitored, and control programs of agricultural practices should be set up, and (2) children and adults should consume wheat from NE, NW, or SW to avoid health risks associated with excessive DON intake. An additional study on seniors is warranted.

Author Contributions: Conceptualization, X.Y. and C.Z.; methodology, P.H. and Z.Z.; software, X.Y.; validation, Z.Z., H.E. and P.H.; formal analysis, H.E.; investigation, J.W.; resources, J.W. and J.Y.; data curation, B.C.; writing-original draft preparation, X.Y.; writing-review and editing, X.Y. and Y.T.; visualization, P.H. and Y.T.; supervision, X.Y. and C.Z.; project administration, X.Y. and J.W.; funding acquisition, X.Y. and J.W. All authors have read and agreed to the published version of the manuscript.

Funding: This research was sponsored by Natural Science Foundation of Shanghai (20ZR1437200), the Natural Science Foundation of China (31871896) and the National Major Project for Agro-product Quality and Safety Risk Assessment (GJFP201800102).

Institutional Review Board Statement: Not applicable.

Informed Consent Statement: Not applicable.

Data Availability Statement: Not applicable.

Conflicts of Interest: The authors declare no conflict of interest. 


\section{References}

1. Gao, T.; Bian, R.; Joseph, S.; Taherymoosavi, S.; Mitchell, D.R.G.; Munroe, P.; Xu, J.; Shi, J. Wheat straw vinegar: A more cost-effective solution than chemical fungicides for sustainable wheat plant protection. Sci. Total Environ. 2020, 725, 138359. [CrossRef]

2. Ji, J.; Zhu, P.; Cui, F.; Pi, F.; Zhang, Y.; Li, Y.; Wang, J.; Sun, X. The antagonistic effect of mycotoxins deoxynivalenol and zearalenone on metabolic profiling in serum and liver of mice. Toxins 2017, 9, 28. [CrossRef]

3. Liu, G.; Zuo, D.-Y.; Yang, P.; He, W.-J.; Yang, Z.; Zhang, J.-B.; Wu, A.-B.; Yi, S.-Y.; Li, H.-P.; Huang, T.; et al. A novel deoxynivalenolactivated wheat Arl6ip4 gene encodes an antifungal peptide with deoxynivalenol affinity and protects plants against Fusarium pathogens and mycotoxins. J. Fungi 2021, 7, 941. [CrossRef]

4. Zhao, Y.; Guan, X.; Zong, Y.; Hua, X.; Xing, F.; Wang, Y.; Wang, F.; Liu, Y. Deoxynivalenol in wheat from the northwestern region in China. Food Addit.Contam. Part B 2018, 11, 281-285. [CrossRef]

5. Pinton, P.; Tsybulskyy, D.; Lucioli, J.; Laffitte, J.; Callu, P.; Lyazhri, F.; Grosjean, F.; Bracarense, A.P.; Kolf-Clauw, M.; Oswald, I.P. Toxicity of deoxynivalenol and its acetylated derivatives on the intestine: Differential effects on morphology, barrier function, tight junction proteins, and mitogen-activated protein kinases. Toxicol. Sci. 2012, 130, 180-190. [CrossRef]

6. Juan, C.; Ritieni, A.; Mañes, J. Occurrence of Fusarium mycotoxins in Italian cereal and cereal products from organic farming. Food Chem. 2013, 141, 1747-1755. [CrossRef]

7. Macías-Montes, A.; Rial-Berriel, C.; Acosta-Dacal, A.; Henríquez-Hernández, L.A.; Almeida-González, M.; Rodríguez-Hernández, Á.; Zumbado, M.; Boada, L.D.; Zaccaroni, A.; Luzardo, O.P. Risk assessment of the exposure to mycotoxins in dogs and cats through the consumption of commercial dry food. Sci. Total Environ. 2020, 708, 134592. [CrossRef]

8. Golge, O.; Kabak, B. Occurrence of deoxynivalenol and zearalenone in cereals and cereal products from Turkey. Food Control 2020, 110, 106982. [CrossRef]

9. Hove, M.; De Boevre, M.; Lachat, C.; Jacxsens, L.; Nyanga, L.K.; De Saeger, S. Occurrence and risk assessment of mycotoxins in subsistence farmed maize from Zimbabwe. Food Control 2016, 69, 36-44. [CrossRef]

10. Li, F.Q.; Wang, W.; Ma, J.J.; Yu, C.C.; Lin, X.H.; Yan, W.X. Natural occurrence of masked deoxynivalenol in Chinese wheat and wheat-based products during 2008-2011. World Mycotoxin J. 2012, 5, 221-230. [CrossRef]

11. NHFPC. Maximum Levels of Mycotoxins in Foods; National Health and Family Planning Commission of the People's Republic of China: Beijing, China, 2017; GB 2761-2017.

12. Zhao, J.; Cheng, T.; Xu, W.; Han, X.; Zhang, J.; Zhang, H.; Wang, C.; Fanning, S.; Li, F. Natural co-occurrence of multi-mycotoxins in unprocessed wheat grains from China. Food Control 2021, 130, 108321. [CrossRef]

13. Makau, C.M.; Matofari, J.W.; Muliro, P.S.; Bebe, B.O. Aflatoxin B1 and deoxynivalenol contamination of dairy feeds and presence of aflatoxin M1 contamination in milk from smallholder dairy systems in Nakuru, Kenya. Int. J. Food Contam. 2016, 3, 6. [CrossRef]

14. Yang, X.; Zhao, Z.; Tan, Y.; Chen, B.; Zhou, C.; Wu, A. Risk profiling of exposures to multiclass contaminants through cereals and cereal-based products consumption: A case study for the inhabitants in Shanghai, China. Food Control 2020, 109, 106964. [CrossRef]

15. Sun, J.; Wu, Y. Evaluation of dietary exposure to deoxynivalenol (DON) and its derivatives from cereals in China. Food Control 2016, 69, 90-99. [CrossRef]

16. JECFA. Safety Evaluation of Certain Mycotoxins in Food; Prepared by the Fifty-Sixth Meeting of the JOINT FAO/WHO Expert Committee on Food Additives (JECFA); World Health Organization: Geneva, Switzerland, 2001.

17. Vidal, A.; Cano-Sancho, G.; Marín, S.; Ramos, A.J.; Sanchis, V. Multidetection of urinary ochratoxin a, deoxynivalenol and its metabolites: Pilot time-course study and risk assessment in Catalonia, Spain. World Mycotoxin J. 2016, 9, 597-612. [CrossRef]

18. Pieters, M.N.; Freijer, J.; Baars, B.-J.; Fiolet, D.C.M.; van Klaveren, J.; Slob, W. Risk assessment of deoxynivalenol in food: Concentration limits, exposure and effects. In Mycotoxins and Food Safety; DeVries, J.W., Trucksess, M.W., Jackson, L.S., Eds.; Springer: Boston, MA, USA, 2002; pp. 235-248.

19. Nielsen, J.K.S.; Vikström, A.C.; Turner, P.; Knudsen, L.E. Deoxynivalenol transport across the human placental barrier. Food Chem. Toxicol. 2011, 49, 2046-2052. [CrossRef]

20. Ministry of Agriculture of the People's Republic of China. Regional Distribution Planning of National Advantage Agricultural Products (2008-2015); Ministry of Agriculture of the People's Republic of China: Beijing, China, 2008.

21. Liu, Y.; Lu, Y.; Wang, L.; Chang, F.; Yang, L. Occurrence of deoxynivalenol in wheat, Hebei province, China. Food Chem. 2016, 197, 1271-1274. [CrossRef]

22. Liu, J.; Sun, L.; Zhang, J.; Guo, J.; Chen, L.; Qi, D. Aflatoxin B, zearalenone and deoxynivalenol in feed ingredients and complete feed from central China. Food Addit. Contam. Part B Surveill. 2016, 9, 91-97. [CrossRef]

23. Wu, L.; Wang, B. Transformation of deoxynivalenol and its acetylated derivatives in Chinese steamed bread making, as affected by $\mathrm{pH}$, yeast, and steaming time. Food Chem. 2016, 202, 149-155. [CrossRef]

24. Li, R. The quality of Shanghai grain whoes $80 \%$ supplied by other place is guaranteed. Xinmin Evening News, 19 June 2012 .

25. NHFPC; National Standards of People's Republic of China. Determination of deoxynivalenol and Its Acetylated Derivatives in Food; National Health and Family Planning Commission of the People's Republic of China: Beijing, China, 2016.

26. Dong, R.; Zhou, T.; Zhao, S.; Zhang, H.; Zhang, M.; Chen, J.; Wang, M.; Wu, M.; Li, S.; Chen, B. Food consumption survey of Shanghai adults in 2012 and its associations with phthalate metabolites in urine. Environ. Int. 2017, 101, 80-88. [CrossRef] 
27. Wang, L.; Zhang, Q.; Yan, Z.; Tan, Y.; Zhu, R.; Yu, D.; Yang, H.; Wu, A. Occurrence and quantitative risk assessment of twelve mycotoxins in eggs and chicken tissues in China. Toxins 2018, 10, 477. [CrossRef]

28. Guo, S.; Ma, S.; Chen, Y. State and trend of grain product of main grain productive area and developing countermeasures in China. Res. Agric. Mod. 2006, 27, 1-6.

29. Silva, M.V.; Pante, G.C.; Romoli, J.C.Z.; de Souza, A.P.M.; Rocha, G.H.O.d.; Ferreira, F.D.; Feijó, A.L.R.; Moscardi, S.M.P.; de Paula, K.R.; Bando, E. Occurrence and risk assessment of population exposed to deoxynivalenol in foods derived from wheat flour in Brazil. Food Addit.Contam. Part. A 2018, 35, 546-554. [CrossRef]

30. Serbian Regulation. Maximum allowed contents of contaminants in food and feed. Off. Bull. Repub. Serb. 2011, 28, 1-16.

31. CAC. 38th Session of the Codex Alimentarius Commission, Maximum Levels of Toxins Produced by A Certain Mould that Can Grow on Grains, Flours, and Cereal-Based Foods for Infants and Young Children; Codex Alimentarius Commission: Geneva, Switzerland, 2015.

32. EC. Commission Regulation (EC) No. 1881/2006, Setting Maximun Levels for Certain Contaminants in Foodstuffs; European Commission: Brussels, Belgium, 2006.

33. Han, Z.; Nie, D.; Ediage, E.N.; Yang, X.; Wang, J.; Chen, B.; Li, S.; On, S.L.W.; De Saeger, S.; Wu, A. Cumulative health risk assessment of co-occurring mycotoxins of deoxynivalenol and its acetyl derivatives in wheat and maize: Case study, Shanghai, China. Food Chem. Toxicol. 2014, 74, 334-342. [CrossRef]

34. Škrbić, B.; Živančev, J.; Đurišić-Mladenović, N.; Godula, M. Principal mycotoxins in wheat flour from the Serbian market: Levels and assessment of the exposure by wheat-based products. Food Control 2012, 25, 389-396. [CrossRef]

35. Ok, H.E.; Choi, S.-W.; Chang, H.J.; Chung, M.-S.; Chun, H.S. Occurrence of five 8-ketotrichothecene mycotoxins in organically and conventionally produced cereals collected in Korea. Food Control 2011, 22, 1647-1652. [CrossRef]

36. Almeida, A.P.d.; Lamardo, L.C.A.; Shundo, L.; Silva, S.A.d.; Navas, S.A.; Alaburda, J.; Ruvieri, V.; Sabino, M. Occurrence of deoxynivalenol in wheat flour, instant noodle and biscuits commercialised in Brazil. Food Addit.Contam. Part. B 2016, 9, 251-255. [CrossRef]

37. Dong, F.; Qiu, J.; Xu, J.; Yu, M.; Wang, S.; Sun, Y.; Zhang, G.; Shi, J. Effect of environmental factors on Fusarium population and associated trichothecenes in wheat grain grown in Jiangsu province, China. Int. J. Food Microbiol. 2016, 230, 58-63. [CrossRef]

38. Biodiversity and Plant Pathogens and Conservation. Available online: https://www.apsnet.org/edcenter/apsnetfeatures/Pages/ ICPP98Ingram.aspx (accessed on 11 October 2021).

39. Chakraborty, S.; Newton, A.C. Climate change, plant diseases and food security: An overview. Plant Pathol. 2011, 60, 2-14. [CrossRef]

40. Xu, W.; Han, X.; Li, F. Co-occurrence of multi-mycotoxins in wheat grains harvested in Anhui province, China. Food Control 2019, 96, 180-185. [CrossRef]

41. Cui, L.; Selvaraj, J.N.; Xing, F.; Zhao, Y.; Zhou, L.; Liu, Y. A minor survey of deoxynivalenol in Fusarium infected wheat from Yangtze-Huaihe river basin region in China. Food Control 2013, 30, 469-473. [CrossRef]

42. Wang, X.; Yang, D.; Qin, M.; Xu, H.; Zhang, L.; Zhang, L. Risk assessment and spatial analysis of deoxynivalenol exposure in Chinese population. Mycotoxin Res. 2020, 36, 419-427. [CrossRef]

43. JECFA. Safety Evaluation of Certain Food Additives and Contaminants; World Health Organization: Geneva, Switzerland, 2014; Volume 68.

44. Herrera, M.; Bervis, N.; Carramiñana, J.J.; Juan, T.; Herrera, A.; Ariño, A.; Lorán, S. Occurrence and exposure assessment of aflatoxins and deoxynivalenol in cereal-based baby foods for infants. Toxins 2019, 11, 150. [CrossRef]

45. EFSA Panel on Contaminants in the Food Chain. Risks to human and animal health related to the presence of deoxynivalenol and its acetylated and modified forms in food and feed. EFSA J. 2017, 15, e04718.

46. Rodríguez-Carrasco, Y.; Ruiz, M.J.; Font, G.; Berrada, H. Exposure estimates to Fusarium mycotoxins through cereals intake. Chemosphere 2013, 93, 2297-2303. [CrossRef]

47. Chen, C.; Turna, N.S.; Wu, F. Risk assessment of dietary deoxynivalenol exposure in wheat products worldwide: Are new codex don guidelines adequately protective? Trends Food Sci. Technol. 2019, 89, 11-25. [CrossRef]

48. Ji, X.; Yang, H.; Wang, J.; Li, R.; Zhao, H.; Xu, J.; Xiao, Y.; Tang, B.; Qian, M. Occurrence of deoxynivalenol (DON) in cereal-based food products marketed through e-commerce stores and an assessment of dietary exposure of Chinese consumers to DON. Food Control 2018, 92, 391-398. [CrossRef]

49. Wang, W.; Zhu, J.; Shao, B.; Li, F. Probabilistic assessment of dietary exposure to both deoxynivalenol and zearalenone from cereal-based products in Chinese populations. Zhonghua Yu Fang Yi Xue Za Zhi [Chin. J. Prev. Med.] 2015, 49, $223-227$.

50. Deng, C.; Li, C.; Zhou, S.; Wang, X.; Xu, H.; Wang, D.; Gong, Y.Y.; Routledge, M.N.; Zhao, Y.; Wu, Y. Risk assessment of deoxynivalenol in high-risk area of China by human biomonitoring using an improved high throughput UPLC-MS/MS method. Sci. Rep. 2018, 8, 3901. [CrossRef]

51. Wang, X.; Liang, J.; Cao, P.; Zhou, S.; Wu, A.; Gao, P.; Xu, H.; Liu, Z.; Gong, Y. Biomonitoring study of deoxynivalenol exposure in Chinese inhabitants. Int. J. Environ. Res. Public Health 2019, 16, 2169. [CrossRef]

52. Wang, X.; Chen, Z.; Zhou, S.; Gao, P.; Cao, F.; Xu, H.; Liang, J. Deoxynivalenol contamination in ready-to-eat cereal-based foods and exposure assessment in inhabitants of Anhui province. Food Nutr. China 2019, 25, 15-19.

53. Qiu, J.-b.; Sun, J.-T.; Yu, M.-Z.; Xu, J.-H.; Shi, J.-R. Temporal dynamics, population characterization and mycotoxins accumulation of Fusarium graminearum in Eastern China. Sci. Rep. 2016, 6, 36350. [CrossRef] 
54. Assunção, R.; Martins, C.; Vasco, E.; Jager, A.; Oliveira, C.; Cunha, S.C.; Fernandes, J.O.; Nunes, B.; Loureiro, S.; Alvito, P. Portuguese children dietary exposure to multiple mycotoxins-An overview of risk assessment under mycomix project. Food Chem. Toxicol. 2018, 118, 399-408. [CrossRef]

55. Djekic, I.; Udovicki, B.; Gajdoš Kljusurić, J.; Papageorgiou, M.; Jovanovic, J.; Giotsas, C.; Djugum, J.; Tomic, N.; Rajkovic, A. Exposure assessment of adult consumers in Serbia, Greece and Croatia to deoxynivalenol and zearalenone through consumption of major wheat-based products. World Mycotoxin J. 2019, 12, 431-442. [CrossRef]

56. Ortiz, J.; Jacxsens, L.; Astudillo, G.; Ballesteros, A.; Donoso, S.; Huybregts, L.; De Meulenaer, B. Multiple mycotoxin exposure of infants and young children via breastfeeding and complementary/weaning foods consumption in Ecuadorian highlands. Food Chem. Toxicol. 2018, 118, 541-548. [CrossRef]

57. Viegas, S.; Assunção, R.; Nunes, C.; Osteresch, B.; Twarużek, M.; Kosicki, R.; Grajewski, J.; Martins, C.; Alvito, P.; Almeida, A.; et al. Exposure assessment to mycotoxins in a Portuguese fresh bread dough company by using a multi-biomarker approach. Toxins 2018, 10, 342. [CrossRef] 